\section{POS1473-HPR SELF- AND SHARED-MANAGEMENT INTERVENTIONS FOR CHILDREN, YOUNG PEOPLE, AND FAMILIES LIVING WITH RHEUMATIC AND MUSCULOSKELETAL DISEASES: AN INTEGRATIVE REVIEW}

S. Stones ${ }^{1}$ on behalf of iSMART Research Group. ${ }^{1}$ University of Leeds, School of Healthcare, Leeds, United Kingdom

Background: Self-management refers to the manner in which individuals manage the symptoms, treatment, physical and psychosocial impact of long-term conditions (LTCs). The importance of equipping children and young people living with LTCs, like rheumatic and musculoskeletal diseases (RMDs) with the capacity to self-manage is increasingly recognised in the literature, and in conversation. In addition, there is a strong case to support families who assume a shared-management role for their child. However, there is a limited understanding of interventions designed to improve self- and shared-management capacity in this population, prompting for a review of the literature, across multiple study designs.

Objectives: The aim of this integrative review was to identify and describe interventions promoting self-management of RMDs by children and young people, and shared-management of RMDs by families.

Methods: The integrative review followed a six-stage process [1]. Studies published since 2010 were identified through a search of eight bibliographic databases. Studies reporting on any paediatric-onset RMD were included, as were those in multiple condition areas where RMDs were included in the analysis. Twenty-six articles met the inclusion criteria: 24 research articles reporting on 17 interventions, and two review articles containing a further four research articles. The methodological quality of included articles was assessed using the Mixed Methods Appraisal Tool, and a thematic synthesis was undertaken.

Results: Most study participants were CYP and families living with JIA. A minority of studies included CYP and families living with other RMDs, as well as chronic pain, type 1 diabetes mellitus, epilepsy, sleeping disorder, and cancer. Around half of the articles reported a specific theory and/or model or framework guiding the intervention. Interventions tended to be focussed at either CYP or families, with few designed to span the lifecourse from birth to young adulthood, while supporting all members of the family unit. Intervention types included: decisional aids; comic educational book; family retreat weekend; internet- and group-based cognitive behavioural programme; internet-based peer mentoring intervention; internet-based self-guided self-management intervention with weekly social support; internet-based electronic patient-reported outcome platform; smartphone applications; telenursing intervention; therapeutic recreational camp; therapeutic family nursing conversations; transition programme/clinic; and video gamesbased task-orientated activity training.

Conclusion: This integrative review identified a range of interventions that have been evaluated to promote self- and shared management of RMDs by CYP and their families. There is a noticeable lack of emphasis on targeting the whole lifecourse for CYP, as well as supporting both CYP and families as they manage their RMD. Further work is needed to explore the underlying mechanisms which dictate how self- and shared-management interventions influence outcomes for CYP and families, under differing contexts, since this was overlooked by the majority of included studies.

REFERENCES:

[1] De Souza et al. Integrative review: What is it? How to do it? Einstein (São Paulo) 2010; 8(1): 102-106.

Acknowledgements: This work formed part of a PhD study funded by the University of Leeds.

Disclosure of Interests: Simon Stones Speakers bureau: Janssen, Consultant of: Envision Pharma Group

DOI: 10.1136/annrheumdis-2021-eular.3824

\section{HPR Patients' perspectives, functioning and health (descriptive: qualitative or quantitative)}

\section{POS1474-HPR PERSONAL EXPERIENCES WITH DIAGNOSTIC DELAY AMONG AXIAL SPONDYLOARTHRITIS PATIENTS - A QUALITATIVE STUDY}

C. Dubé ${ }^{1}$, K. Lapane ${ }^{1}$, K. Ferrucci ${ }^{1,2}$, A. Beccia ${ }^{1}$, S. Khan ${ }^{1}$, E. Yi ${ }^{3}$, J. Kay ${ }^{1,4,5}$, K. A. Kuhn ${ }^{6}$, A. Ogdie ${ }^{7}$, S. H. Liu'. ${ }^{1}$ University of Massachusetts Medical School, Population and Quantitative Health Sciences, Worcester, United States of America; ${ }^{2}$ University of Massachusetts Medical School, Clinical and Population Health Research Program, Graduate School of Biomedical Sciences, Worcester, United States of America; ${ }^{3}$ Novartis Pharmaceuticals Corporation, HE\&OR and Medical Access, East Hanover, United States of America; ${ }^{4}$ University of Massachusetts Medical School, Division of Rheumatology, Department of Medicine, Worcester, United States of America; ${ }^{5}$ UMass Memorial Medical Center, Rheumatology Center, Worcester, United States of
America; ${ }^{6}$ University of Colorado School of Medicine, Department of Medicine, Denver, United States of America; ${ }^{7}$ University of Pennsylvania Perelman School of Medicine, Epidemiology and Biostatistics, Center for Clinical Epidemiology and Biostatistics, Philadelphia, United States of America

Background: The estimated prevalence of axial Spondyloarthritis (axSpA) in the U.S. is 0.4 to 1.3 percent. Undiagnosed axSpA patients suffer from symptoms on average 7 to 10 years, which can also contribute to psychological suffering and healthcare burden due to the prolonged search for diagnosis and treatment. Objectives: To explore the experiences of diagnostic delay of axSpA patients as part of the SpondyloArthritis Screening and Early Detection (SpA-SED) Study. Methods: We conducted exploratory semi-structured patient focus groups. English-speaking participants $\geq 18$ years of age with a rheumatologist-verified clinical diagnosis of axSpA were recruited from three rheumatology practices in Massachusetts, Colorado, and Pennsylvania. Six focus groups were conducted with 26 total participants (16 men, 10 women, age range 21-76 years). Discussions ranged from 1.33 to 2.13 hours. Verbatim transcripts were deidentified, cleaned and coded using NVivo qualitative software. A coding list was generated and summary themes were constructed.

Results: Participants described meandering and frustrating journeys in search of a diagnosis. When doctors gave up, it was experienced by patients as profoundly negative. Intermittent axSpA symptoms confused some physicians and caused some patients to either delay seeking medical care (e.g., sporadic flare-up) or use dramatic language to convey the magnitude of the impact on their symptoms. Patients explained their experiences where physicians presumed that patients were trying to obtain narcotics or were "imagining/exaggerating" symptoms. Early symptom stories fell into five areas of importance for patients: pain, stiffness and lack of mobility, impact on sleep, impact on daily life, and changes with weather Tenacity on the part of the patient and/or their family, patient research and confidence to challenge their physicians were important. Self-advocacy was challenging but necessary and particularly difficult when patients were sick. During the typically lengthy time that participants waited to be diagnosed, they experienced frustration and mental suffering due to lack of answers and/or not being heard, believed, or taken seriously. Some participants described the fatigue they experienced after trying without success to obtain a diagnosis or receive treatment. Early administration of a definitive diagnostic test or screening tools for axSpA would have alleviated both physical and emotional suffering for these participants. Conclusion: Overall, participants expressed satisfaction with physicians who sought to understand them and believed them, took them seriously, and did not give up even with long delays. Patients with axSpA described significant suffering prior to diagnosis which could have been prevented and treated. Further research is needed with axSpA patients who are early in their diagnostic journey to determine best practices to support patients and reduce diagnostic delay Disclosure of Interests: Catherine Dubé Grant/research support from: Novartis, as personnel on such studies, Kate Lapane: None declared, Katarina Ferrucci: None declared, Ariel Beccia: None declared, Sara Khan: None declared, Esther Yi Employee of: Novartis Pharmaceuticals, Jonathan Kay Consultant of: AbbVie, Inc.; Boehringer Ingelheim GmbH; Celltrion Healthcare Co. Ltd.; Jubilan Radiopharma; Merck \& Co.,Inc.; Pfizer Inc.; Samsung Bioepis; Sandoz Inc.; Scipher Medicine; UCB, Inc., Grant/research support from: (paid to UMass Medical School) Gilead Sciences Inc.; Novartis Pharmaceuticals Corp.; Pfizer Inc., Kristine A. Kuhn Consultant of: UCB, Eli Lilly, Novartis, Grant/research support from: Pfizer, Alexis Ogdie Consultant of: Abbvie, Amgen, BMS, Celgene, Corrona, Gilead, Janssen, Lilly, Novartis, Pfizer, UCB, Grant/research support from Pfizer to Penn, Novartis to Penn, Amgen to Forward/NDB, Shao-Hsien Liu Grant/ research support from: Novartis DOI: 10.1136/annrheumdis-2021-eular.612

\section{POS1475-HPR EFFECT OF ARGENTINE TANGO PRACTICE ON TOTAL PHYSICAL ACTIVITY TIME IN PATIENTS WITH CHRONIC INFLAMMATORY RHEUMATISM: A PILOT STUDY}

N. Darmant ${ }^{1}$, F. Fayet ${ }^{1}$, C. Lambert ${ }^{2}$, B. Pereira ${ }^{2}$, M. Rodere ${ }^{1}$, A. Fan ${ }^{1}$ M. Soubrier ${ }^{1}, \mathrm{M}$. Duclos ${ }^{3} .{ }^{1} \mathrm{CHU}$ Gabriel-Montpied, Rhumatologie, ClermontFerrand, France; ${ }^{2} \mathrm{CHU}$ Gabriel-Montpied, Biostatistics Unit, Clermont-Ferrand, France $;{ }^{3} \mathrm{CHU}$ Gabriel-Montpied, Sports Medicine, Clermont-Ferrand, France

Background: Most patients with chronic inflammatory rheumatism (CIR) have a physical activity (PA) level below recommendations [1,2]. Currently, adapted structures offer a range of activities supervised by adapted physical activity educators. To the best of our knowledge, Argentinean tango is not yet offered in these structures.

Objectives: The objective of this pilot study was to study the effect of 24 consecutive sessions of Argentinean tango on the total PA level in patients with CIR, including rheumatoid arthritis (RA) and spondyloarthritis (AS).

Methods: In this controlled, randomized, open-label, clinical trial with two parallel arms, patients were required to attend two tango sessions per week, 